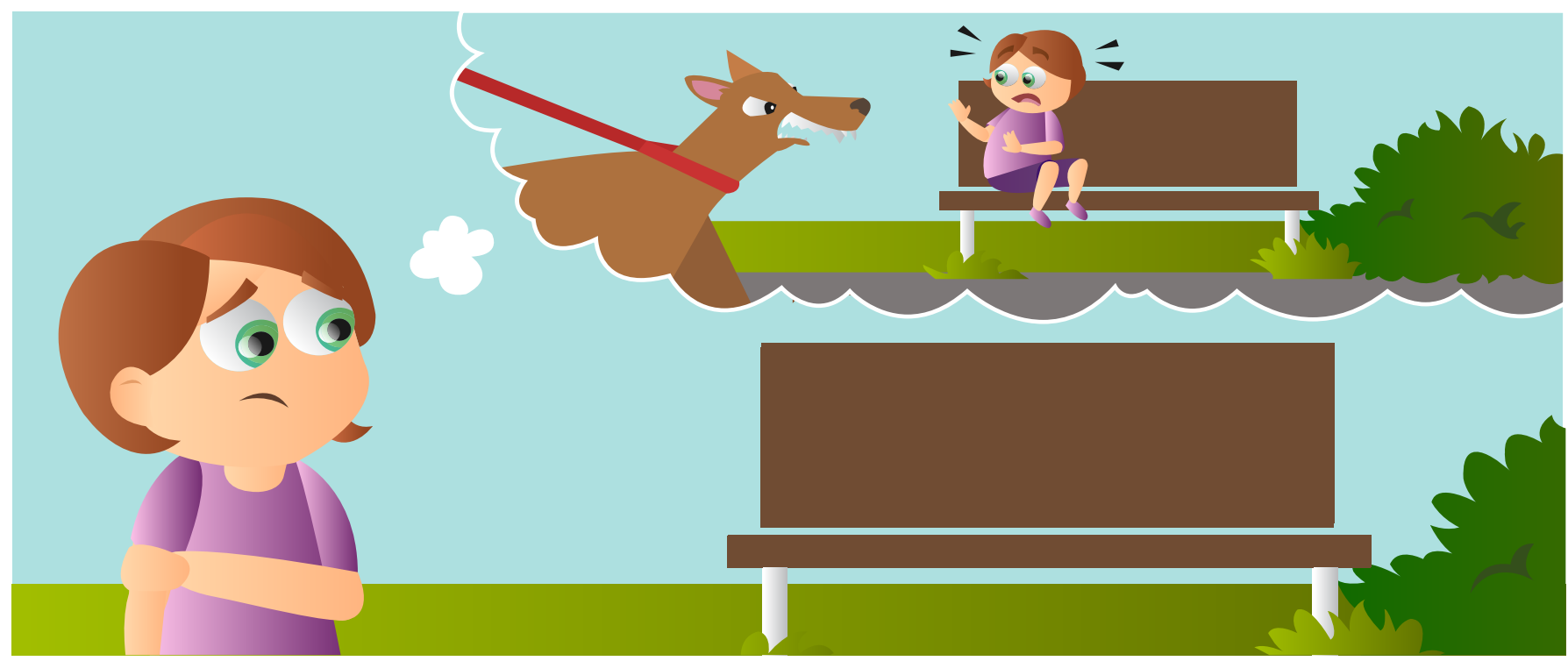

\title{
REMEMBERING OR FORGETTING: THE LIFETIME OF MEMORIES
}

\section{Pablo Mendez*}

Department of Basic Neurosciences, University of Geneva, Geneva, Switzerland

\section{REVIEWED BY:}

If we walk down a street where we were once bitten by a dog, we feel fear. This is because our brains are great at creating associations. The street and the dog bite become linked in the brain's information storage. Our brains can even remember this linkage forever! But, how is the lifetime of memories adjusted? The fearful experience leaves a trace that is recorded in a small group of neurons in the brain. Every memory has its own group of neurons, composed of different types of cells. In the laboratory, we performed experiments to change the number of neurons in these groups. According to our results, in a particular part of the brain called the hippocampus, the number of neurons in a group is important for memory. Adding neurons to the group improves memory while removing them accelerates forgetting. A special type of neuron in the brain controls the size of these groups. We think that this process regulates the lifetime of memories.

\section{MEMORIES ARE STORED IN OUR BRAINS}

Our brains are little mazes of brain cells called neurons. The human brain is composed of around 100 billion neurons. If neurons were the size of a 
RECALL

To form a memory, our brain must first transform experience into something that can be stored in our brain. Recall is the process that we performed to get and bring back that information from the past. grain of sand (they are actually much smaller!) we could fill around 8,500 soda cans with neurons from one single human brain. The job of neurons is to send signals between cells. Each of our neurons has about 10,000 opportunities to form connections with neighboring neurons. And not all neurons are alike. While some neurons send signals to other cells telling them to be active, others can inhibit their neighbors and prevent them from sending out signals. As researchers, we are interested in how the brain functions and saves memories using this complicated maze of neurons. We are beginning to understand that only some neurons, located in certain parts of the brain, carry the memory of people, facts, and places, which define the history of each one of us.

\section{DIFFERENT TYPES OF MEMORY}

We have the ability to form two different types of long-lasting memories. First, we can learn to perform certain actions, such as talking, riding a bike, or playing a musical instrument, and we will remember how to do these things forever. We learn these actions in a way that lets us unconsciously repeat them, meaning that we can perform these actions without needing to think about them to remember them. However, other types of memories require something called intentional recall. This means that we need to think about these things to remember them. Examples of this form of memory are things like our first-grade teacher's name, the meaning of words, or the street where we were attacked by a dog.

\section{LEARNING BY ASSOCIATION}

In our laboratory, we study the kind of memories that we can intentionally recall. In our everyday lives, we very often form this type of memory by a process called association. Learning by association was first studied by a Russian scientist named Ivan Pavlov. Pavlov played a clicking sound to hungry dogs before feeding them meat. He noticed that the first time he did that the dogs produced saliva when the meat was given to them (as we all do, to prepare us to digest food). But the dogs would not salivate in response to the clicking sound alone (they had no reason to do that). However, after making the clicking sound and giving the dogs the meat a number of times, the dogs started salivating in response to the clicking sound, before receiving food. This is because the dogs learned the association between the clicking sound and the meat, even though these two things were previously unrelated for them. This form of learning by association exists in most animals (including honey bees, sea slugs, and mice) and of course, in humans. Walking down a particular street makes you feel completely normal until the day you are bitten by a dog on that street. From that moment on and for a long time into the future, you will feel fear when you walk down that street because you associate that place with the pain caused by the fierce dog. 


\section{HIPPOCAMPUS}

An ancient region of the brain important to control emotions, motivation, and memory. It processes the information of the space that surrounds us and forms spatial maps that, for example, allow you to find your way from home to school.

\section{AMNESIA}

Loss of memory caused by disease, drugs, or traumatic experiences. It is typically associated with damage to a region of the brain that includes the hippocampus. Other intellectual skills remain intact despite the inability to remember.

\section{DENTATE GYRUS}

A small part of the hippocampus. It is composed of hundreds of thousands of neurons that receive information about the outside world. The dentate gyrus is essential to the formation of new memories. The dentate gyrus is one of the few places of the brain where new neurons are formed throughout life.

\section{A BRAIN REGION CALLED THE HIPPOCAMPUS IS THE} BIRTHPLACE OF MEMORIES

Getting bitten by a dog on the street is a good example of the kind of memory we study in the laboratory. We use the great memory skills of mice to train them to fear dangerous places (like the street with the fierce dog) or to prefer safer places (a different, quiet street). Several days after training them, the mice tell us that they remember the frightening location by showing fear even if the danger is no longer present (the same way we fear the street even if cannot see the dog). If the mice are placed in a different, "safe" location, they show no fear. Some time ago, it was discovered that this fear memory is created in a certain part of the brain called the hippocampus, named after it's sea horse-like shape (Hippocampus is the name given by scientists to the small tropical fish called sea-horses) [1] Unfortunately, we have several examples of people who, following accidents or illnesses, have severe damage to the hippocampus (or hippocampi in plural, as we have one hippocampus on each side of the brain). Damage to the hippocampus leaves people unable to form new memories; therefore, they become amnesic, meaning they have amnesia, which you may have heard of. Also, Alzheimer's disease, which causes neuron death in the hippocampus, impairs the ability to remember recent events and causes a progressive memory loss.

\section{NOT ALL AT ONE TIME: A SMALL GROUP OF NEURONS FOR EACH MEMORY}

So, what happens in the hippocampus when mice learn to remember a fearful location? A small fraction of the neurons in a specific part of the hippocampus called the dentate gyrus becomes active. In the dentate gyrus, neurons are normally very quiet, but a small group of them (less than $10 \%$ of the neurons in the dentate gyrus) show high levels of activity when mice explore a new location. In the lab, we can identify these neurons (Figure 1). Interestingly, the small groups of neurons in dentate gyrus that become active when mice explore new locations are not always the same. If, the following day, mice explore a different location, a different group of neurons will become active [2]. Under these circumstances, each new location explored will activate a particular group of neurons.

\section{CONTROLLING NEURONS WITH LIGHT}

But what are these groups of activated neurons good for? To answer this question, many laboratories around the world have used optogenetics, a technique that allows scientists to switch the activity of neurons on or off by flashing light on them. Optogenetics is a mix of a laboratory technique and laser lights. The laboratory technique involves special light-sensitive proteins (similar to those in our eyes) that are modified and put into neurons. Flashing light on 


\section{FIGURE}

A. The location of the hippocampus is shown in the cartoon of the mouse brain and underneath, a microscope image of a mouse brain is shown with the hippocampus stained in green (the white bar in the bottom right represents $1 \mathrm{~mm}$ ). The area inside the square white dots is the dentate gyrus, which is shown bigger in B,C. In the dentate gyrus, a low fraction of neurons become active when mice go from a resting state

B. to active exploration of a new location C. Using a laboratory technique, active neurons start emitting green light (green circles in the lower part of B,C.) and can be distinguished from inactive neurons that remain dark (white circles).

\section{ENGRAM}

The physical mark that experiences leave in the brain. The mark is both physical (neurons change their shape) and chemical (neurons change their composition). The engram is used by the brain to store and remember. The engram is difficult to observe because it is hidden in some of the billions of neurons in the brain.

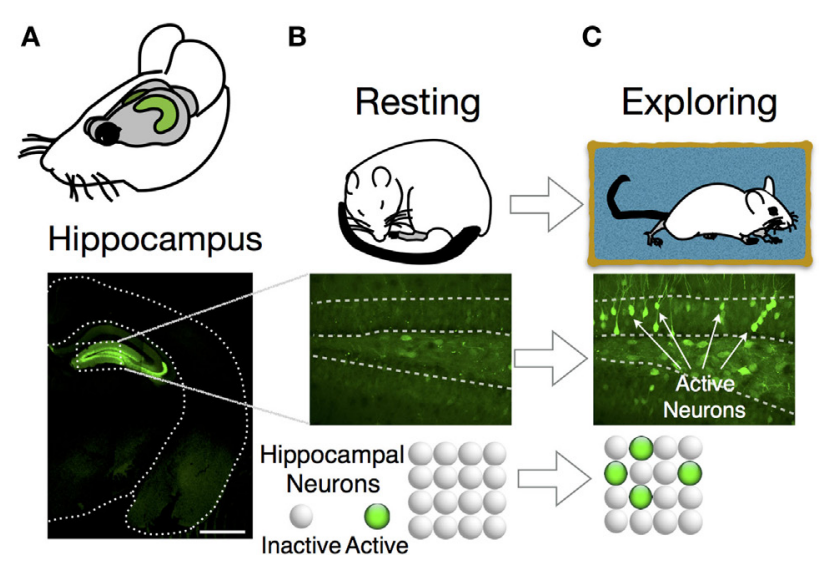

FIGURE 1

these neurons will then change their electric properties, making them active or inactive, "on" or "off" [3]. This is called an optogenetic switch that turns neurons on or off with flashes of light.

\section{MANIPULATING MEMORIES}

Scientists have used optogenetics to study memory. They put an optogenetic switch into the small group of neurons that were active in the mice that learned to fear a certain location. Several days later, when the mice were returned to that location, they used this switch to silence or "turn off" that group of neurons with light. When they did this, the mice showed no fear in the frightening location, meaning they were unable to remember, as if the memory was erased [4]! Without the small group of neurons that was active during memory formation, recall is not possible (Figure 2). Somehow, the fearful experience left a durable imprint in the brain, specifically in that small group of neurons in the hippocampus. This imprint, which scientists call an engram, is what allows mice (and us!) to store memories and makes future recall possible.

\section{WHY JUST A FEW NEURONS FOR A MEMORY?}

What puzzled us was understanding why the engram was formed by only a few neurons. Remember that less than 1 out of each 10 neurons in the dentate gyrus of the hippocampus participates in the storage of a particular memory! Could this have something to do with how long a particular memory will be stored in the brain? To start answering these questions, we used optogenetics to slightly change the number of neurons in the engram. We discovered that adding a few neurons to the engram made mice remember the fearful location for longer periods of time, but fewer neurons weakened the memory. So, the number of neurons in the engram is clearly important for memory! But, how does the brain control the number of neurons involved in a particular memory? 


\section{FIGURE 2}

Mice learn to associate a certain location with a frightening stimulus (for example, a cat). One week later, they show fear when put back in the same location because they remember the fearful experience. The same group of neurons that was active when the mice first saw the cat must be reactivated to cause the memory. If these neurons are silenced (OFF symbols), the mice are unable to recall what happened in the cage and show no fear in the location where they saw the cat.

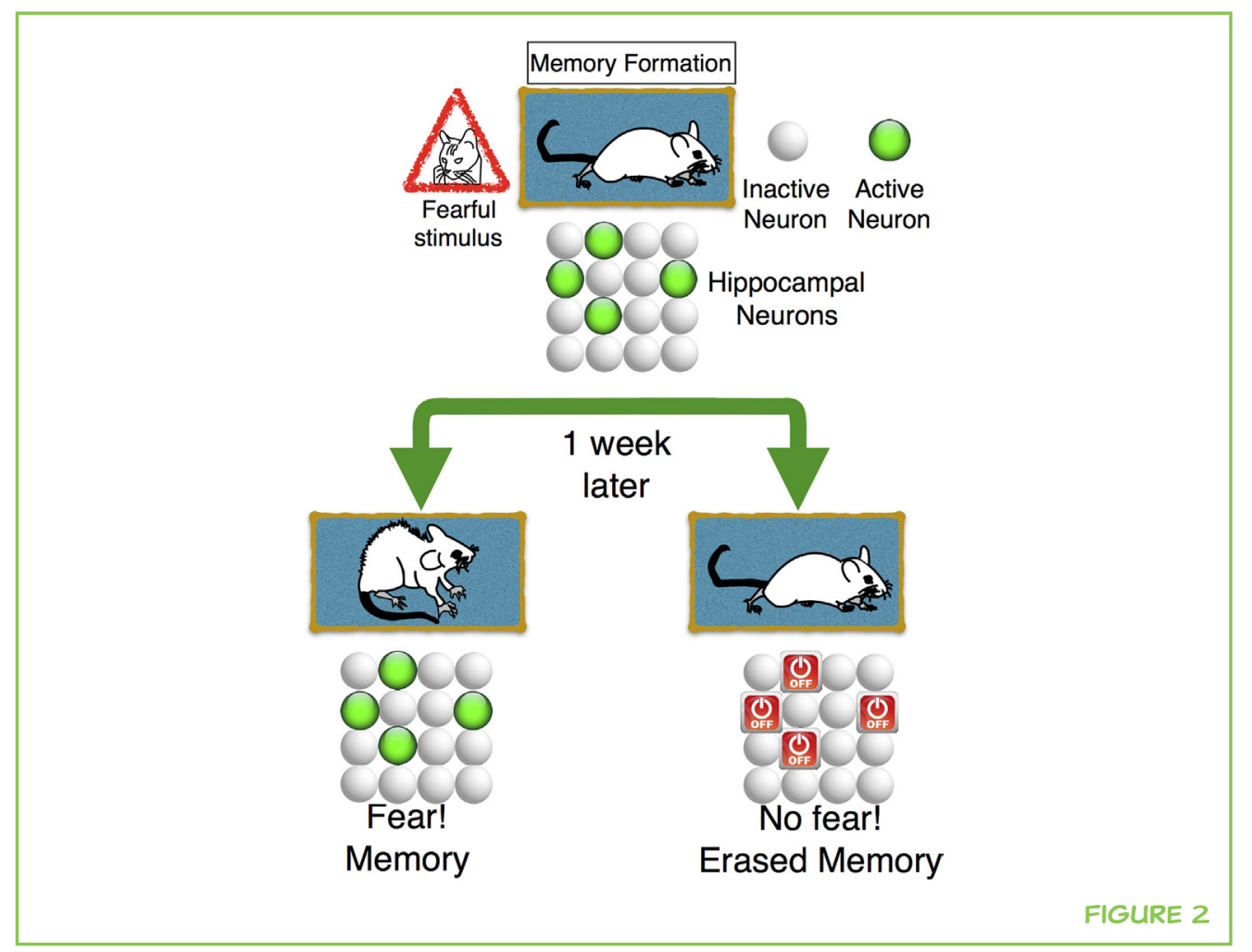

INHIBITORY NEURONS RULE

In the brain, we have different types of neurons. In the hippocampus, the majority of the neurons are excitatory. Excitatory neurons increase the activity of the other neurons they make contact with. But we also have a small fraction of inhibitory neurons in the hippocampus. When they are active, inhibitory neurons tell other neurons to be silent and inactive (Figure 3A). Without inhibitory neurons, our brain would have too much activity going on and would not work properly. Some inhibitory neurons contact an enormous number of other neurons. When we looked in more detail, we discovered that most neurons in the engram were excitatory, but a small fraction were inhibitory. We immediately thought that inhibitory neurons could be controlling the number of neurons in the engram. We manipulated inhibitory neurons during memory formation and made an important finding. When inhibitory neurons were silenced, larger engrams were created and the fear location was remembered for a longer period of time. When we forced inhibitory neurons to be active, fewer neurons were involved in memory and the memory of the fearful location was weaker. Thus, inhibitory neurons can change the number of memory neurons and the lifetime of a memory (Figure 3B).

\section{TO PRESERVE MEMORY, THE BRAIN MUST ADJUST THE NUMBER OF NEURONS INVOLVED}

By varying the number of neurons involved in memory, we were able to make the memory more or less durable! In our study, we demonstrated 


\section{FIGURE 3}

A. Excitatory neurons send activating signals to target neurons (green line). Excitatory neurons can activate inhibitory neurons that in turn silence target neurons (red line). B. Inhibitory neurons control the number of neurons that create fear memory. If inhibition is weakened, more neurons will become active (green) during the making of a fear memory and memory will be stronger. When inhibition is strong, fewer neurons will be involved in memory encoding and memory will be weakened.

POSTTRALMATIC STRESS

\section{DISORDER}

A mental disorder that happens after being exposed to a very difficult or unpleasant experience (a natural disaster for example). Months or years after the experience, patients suffer fearful thoughts, feeling, or dreams related to the traumatic experience. Some scientists think that forcing the forgetting of these very strong memories will help patients of post-traumatic stress disorder.

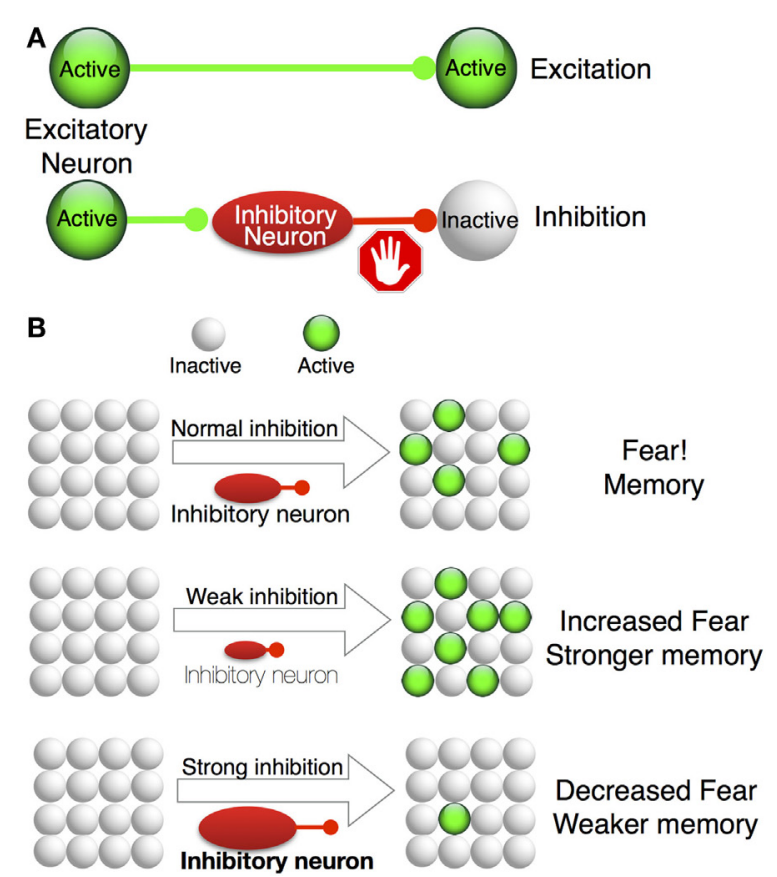

FIGURE 3

that memories encoded by a small number of neurons will be remembered for only a short period of time, while a large number of neurons will give rise to memories that will persist longer [5]. We know that when engrams are beyond a certain size, memory does not work at all. So, our brains need to adjust the number of neurons in the engram, and inhibitory neurons are part of the system controlling engram size. The more we can understand about the mechanisms that are involved with the stability of memories, the closer we get to understand the total storage capacity of our brains. Brain diseases and disorders may lead to memory problems, like those seen in Alzheimer's disease, but may also lead to "excessive" memories (frequently associated with bad experiences) such as in posttraumatic stress disorder. We now plan to investigate whether the memory storage mechanisms we describe in our work are affected in these brain disorders.

\section{ORIGINAL ARTICLE REFERENCE}

Stefanelli, T., Bertollini, C., Luscher, C., Muller, D., and Mendez, P. 2016. Hippocampal somatostatin interneurons control the size of neuronal memory ensembles. Neuron 89:1074-85. doi:10.1016/j.neuron.2016.01.024

\section{REFERENCES}

1. Frankland, P. W., and Bontempi, B. 2005. The organization of recent and remote memories. Nat Rev. Neurosci. 6:119-30. doi:10.1038/nrn1607 
2. Ramirez, S., Liu, X., Lin, P. A., Suh, J., Pignatelli, M., Redondo, R. L., et al. 2013. Creating a false memory in the hippocampus. Science 341:387-91. doi:10.1126/ science.1239073

3. Deisseroth, K. 2011. Optogenetics. Nat. Methods 8:26-9. doi:10.1038/nmeth.f.324

4. Tanaka, K. Z., Pevzner, A., Hamidi, A. B., Nakazawa, Y., Graham, J., and Wiltgen, B. J. 2014. Cortical representations are reinstated by the hippocampus during memory retrieval. Neuron 84:347-54. doi:10.1016/j.neuron.2014.09.037

5. Stefanelli, T., Bertollini, C., Luscher, C., Muller, D., and Mendez, P. 2016. Hippocampal somatostatin interneurons control the size of neuronal memory ensembles. Neuron 89:1074-85. doi:10.1016/j.neuron.2016.01.024

SUBMITTED: 28 September 2016; ACCEPTED: 20 February 2017; PUBLISHED ONLINE: 10 March 2017.

EDITED BY: Jorge Moll, D'Or Institute for Research and Education (IDOR), Brazil

CITATION: Mendez P (2017) Remembering or Forgetting: The Lifetime of Memories. Front. Young Minds 5:4. doi:10.3389/frym.2017.00004

CONFLICT OF INTEREST STATEMENT: The authors declare that the research was conducted in the absence of any commercial or financial relationships that could be construed as a potential conflict of interest.

COPYRIGHT @ 2017 Mendez. This is an open-access article distributed under the terms of the Creative Commons Attribution License (CC BY). The use, distribution and reproduction in other forums is permitted, provided the original author(s) or licensor are credited and that the original publication in this journal is cited, in accordance with accepted academic practice. No use, distribution or reproduction is permitted which does not comply with these terms.

\section{REVIEWED BY}

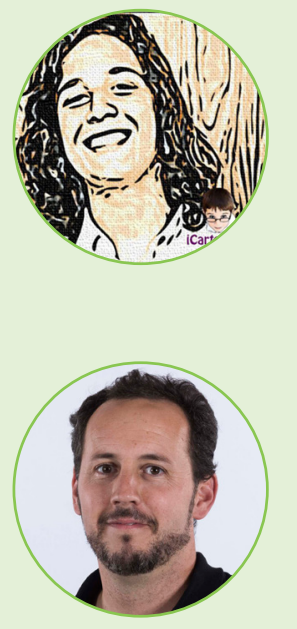

\section{EDUARDO, 13 YEARS OLD}

I live in Rio de Janeiro. I like to play basketball, read, and Star Wars. Despite my father's complaints, I now have long hair. I like my school very much. I often go to the beach with my parents, and every Sunday I watch soccer with my grandma. Vasco is the time of my heart.

\section{AUTHOR}

\section{PABLO MENDEZ}

I am a Spanish neuroscientist now living in Switzerland. I study a part of our brain called hippocampus and how it changes when we store new memories. In particular, I am interested in how the different types of neurons in the hippocampus communicate between them and with the rest of the brain during the formation and recall of memories. Out of the lab, I spent most of the time with my family, reading, hiking, and growing vegetables. *pablo.mendez@unige.ch 